University of Nebraska - Lincoln

DigitalCommons@University of Nebraska - Lincoln

Sociology Department, Faculty Publications

Sociology, Department of

2012

Rotten, Vile, and Depraved! Depictions of Criminality in Superhero

Cartoons

Lisa A. Kort-Butler

University of Nebraska-Lincoln, Ikortbutler2@unl.edu

Follow this and additional works at: https://digitalcommons.unl.edu/sociologyfacpub

Part of the Criminology Commons, and the Social Control, Law, Crime, and Deviance Commons

Kort-Butler, Lisa A., "Rotten, Vile, and Depraved! Depictions of Criminality in Superhero Cartoons" (2012). Sociology Department, Faculty Publications. 188.

https://digitalcommons.unl.edu/sociologyfacpub/188

This Article is brought to you for free and open access by the Sociology, Department of at DigitalCommons@University of Nebraska - Lincoln. It has been accepted for inclusion in Sociology Department, Faculty Publications by an authorized administrator of DigitalCommons@University of Nebraska - Lincoln. 
Published in Deviant Behavior 33 (2012), pp. 566-581; doi: 10.1080/01639625.2011.636718

Copyright (c) 2012 Taylor \& Francis Group. Used by permission.

Submitted February 18, 2011; accepted July 30, 2011.

Support for this research was provided by the Haas Faculty Award,

Department of Sociology, University of Nebraska-Lincoln.

The author thanks Kayla Pritchard for her assistance on this project.

\title{
Rotten, Vile, and Depraved! \\ Depictions of Criminality in Superhero Cartoons
}

\author{
Lisa A. Kort-Butler \\ University of Nebraska-Lincoln, Lincoln, Nebraska, USA \\ Correspondence: Lisa A. Kort-Butler, Department of Sociology, 711 Oldfather Hall, \\ P.O. Box 880324, Lincoln, NE 68588-0324, USA; email lkortbutler2@unl.edu
}

\begin{abstract}
The literature argues that media depictions of crime present messages that conform to and promote the dominant ideology about the causes of crime and the nature of criminality. Most research focuses on television news and adult programs, but little research examines messages about criminality present in children's shows. To fill this gap, a content analysis of children's cartoons was conducted, using episodes of Batman: The Animated Series, Spider-Man, and Justice League Unlimited. Three central themes emerged. First, much criminal activity centers on greed. Second, criminals are aware of right and wrong but pursue crime to meet their own self-interests. Third, criminals are different from law-abiding people. Even if they are flawed or evil, criminals are rational and therefore culpable actors. These shows provide messages about criminality consistent with the dominant ideology.
\end{abstract}

Television is a primary venue through which deviant behavior is socially constructed, as well as a medium through which cultural images about crime and criminality are disseminated and reinforced. In general, the literature argues that media depictions of crime and criminals present messages that conform to and promote the dominant ideology about the nature and motivation for criminal behavior. Most research focuses on television news and adult programming like Law $\mathcal{E}$ Order or America's Most Wanted. Little research has examined the messages about criminality to which people are exposed at an early age. For people who have limited non-media sources of information about crime, like the general child audience, the media becomes even more relevant for defining the socially constructed reality of crime (Surette 2003).

Research on children's programming generally focuses on the amount of violent content young people may see or how depictions of violence may translate to real-world aggressiveness or use of violence by the young viewer (Blumberg et al. 2008). Although the debate continues regarding the effects of television viewing on behavior, it is clear that children's shows contain significant amounts of broadly defined violence. For example, Wilson et al. (2002) analyzed data from National Television Violence Study and found that $97 \%$ of superhero shows depicted violence. However, compared to other children's programs, this violence was more often portrayed as justified or morally correct. 
Superhero shows draw their characters from the realm of comic books. Studies that have investigated the depiction of crime and justice in comic books suggest that these depictions tend to conform to dominant ideologies about justice and support vigilantism so long as the ends justify the means (Adkinson 2008; Coogan 2006; Fingeroth 2004). Less common in this field of study are analyses that contemplate how antagonists are portrayed and how their deviant behaviors are explained (Phillips \& Strobl 2006; Vollum and Adkinson 2003).

According to Surette (1998), the primary difference between print media like comics and electronic visual media like cartoons is not so much in the constructed images, but in the diffusion of the images that electronic media, particularly television, provides. Despite the popularity of the superhero genre in comics and in film, and the interest of scholars in mediated constructions of crime, few, if any, studies have analyzed the images and messages associated with televised animated superheroes. A casual review of superhero shows reveals that they, not surprisingly, regularly deal with crime issues.

A more systematic analysis is warranted in order to reveal how these children's shows construct deviance and criminality. In this article, I first describe the dominant ideology surrounding crime, namely its emphasis on the rational yet evil offender. Second, I review the role of the media in promoting and maintaining this image of the criminal. Third, I present the results of a content analysis of three popular superhero cartoons, focusing on representations of and explanations for criminal offending. Finally, I examine the images and meanings of criminality revealed in these cartoons vis-a'-vis the dominant ideology of crime.

\section{THE DOMINANT IDEOLOGY OF CRIME}

Historically, there have been fluctuations in the prevailing ideology about the nature of crime and criminality. Since the mid-1970s and accelerating during the age of Regan, the pendulum has taken a decidedly neo-classical (in terms of revisiting the "rational" offender) and conservative (in terms of right-leaning policy) swing, and this swing has continued to shape ideology and policy (Hagan 2010; Melossi 2000). This shift in the state of Americans' ideas about criminals and crime control has been variously described as changing "sensibilities" about penal culture (Tonry 2004), the new "culture of control" (Garland 2001), and a "culture of fear" (Simon 2007). Unnever and Cullen (2010) noted that these various theoretical arguments share in common an exposé of the two essential components of the dominant ideology of crime and control associated with the shift. First, the ideology rejects the social welfare paradigm and its associated emphasis on addressing the root causes of crime and rehabilitating offenders. Second, the ideology advocates for harsh punishment of offenders to protect potential individual victims and society-atlarge. The punitive law-and-order shift in political and public rhetoric and in American justice policies is made possible by recasting the nature of the criminal. Arguments in favor of punitive policies almost always invoke themes of individual accountability, personal responsibly, and moral culpability (Tonry 2004:25).

Hence, central to the dominant ideology of crime and control is the associated image of the criminal. Garland (2001) contends that our cultural norms and political priorities are built on an ethos of individual choice and personal freedom, qualities we extend to criminals, deemed to freely and rationally choose their actions. If those choices appear to be irrational or beyond comprehension, the criminals are deemed to be evil or insane 
(Presdee 2000). The label of evil or pathological neatly disguises the challenge posed to rationality by criminal behavior and dismisses the specter of social conditions as causal factors (Garland 2001; Presdee 2000). By these labels, criminals are also "othered"; that is, they are placed in an entirely different category from $u s$, allowing $u s$ to exclude them (Ismaili 2003). The criminal is "the public enemy," a monstrosity, "morally repugnant," and "a deadly threat to the moral order" (Melossi 2000). The criminal is out-and-out bad or has a personal deficit that makes them act badly (Melossi 2000). In sum, the dominant ideology of crime locates the causes of criminal behavior within the individual, eschews the effects of social conditions, and converges on the rational yet evil offender who undermines social well-being and the moral order.

\section{MEDIA CONSTRUCTIONS OF CRIME}

\section{Ideology to Image and Back Again}

Hagan (2010) uncovered the active framing of criminals and social control by political leaders and others in positions of power, which took place during the Reagan era and the years that followed. Importantly, during this process, the media relied heavily on state managers as experts on the crime situation and as the primary definers of crime (Welsh et al. 1997:488). In turn, the definitions provided by state managers are "transformed, transmitted, and reproduced according to the imperatives of the dominant ideology, thereby determining what is socially thinkable" about criminals and their control (Welsh et al. 1997:490, emphasis in original). Although empirical research is somewhat equivocal about whether the media react to or directly motivate public opinion about crime and justice (Frost 2010), in either case it is clear that the media play a prominent role in socially constructing and shaping ideology about crime, its causes, and its control in ways that uphold the status quo (Dotter 2002; Surette 1998).

Indeed, media representations are the primary way in which most Americans learn about and make sense of crime and justice (Barak 1994), even as the cultural line between the real and the virtual continues to shift (Dotter 2002). For example, in mass-produced popular culture, violence is depicted for violence's sake and the meaning associated with it is at best ideologically superficial and at worst ideologically manipulative (Lynch and Krzycki 1998). In 30 years of the Cultural Indicators Project, levels of television violence have remained relatively stable, while violence has been often presented without context for its causes or consequences for the actors involved (Shanahan 2004). As a result of the decontextualization of criminal events, "all that is left of crime is excitement and desire as crime itself becomes transformed into a commodity" (Presdee 2000:26). Deviance and crime are thus commodities for communicating information to consumers and entertaining them, and both forms offer ideological content (Dotter 2002).

Regardless of the crime and associated evidence, the media usually follow the established narrative about criminality, thereby reproducing and reinforcing the assumptions that legitimate the present criminal justice system (Lofquist 1997). These narratives have come to center on the malevolent individual with whom law-abiding people cannot identify. Cavender (2004) noted that in the 1970s, coinciding with the shift in political rhetoric, a shift in the depiction of criminal offenders occurred, renewing the process of "othering" criminals. Criminal offenders are cast as villains who personify the evil side of humanity. Greed, revenge, and mental illness are common motivations (Surette 1998). The over- 
arching message of the media is that crime is committed by predators whose behavior is rooted in personal faults, who freely choose their behavior, who are unconstrained by social rules and moral values, and who are ultimately different from us (Surette 1994). The causes of criminal offending are located within the individual, and the connection between crime and larger social forces are rarely illuminated (Sacco 1995). The image of the criminal is a projection of the "exceptional and unrepresentative criminals" people have seen or read about across various forms of media, eliciting support for punitive policies (Morris 1997:107, emphasis added).

\section{Previous Research on Media Representations}

In adult television shows, explanations for criminality tend to conform to dominant conceptions of criminals as different or disturbed, but nonetheless personally responsible for their behavior. In reality shows like America's Most Wanted, offenders are shown as dangerous and disturbed, lacking remorse, and described as physically ugly (Cavender 1998). Offenders are largely motivated by greed, although emotional motives like jealousy are also offered (Cavender and Bond-Maupin 1993). Programs like COPS also focus heavily on violence and bizarre behavior, emphasizing the sensational rather than the mundane aspects of crime (Koosistra et al. 1998). Reality shows like COPS occasionally portray a different kind of offender, one who is unruly or part of routine disorder, but police interactions with these individuals nevertheless provide a glimpse into how the other half lives (Donovan 1998). Even when reality shows offer a backstory, they tend to be caricatures that reproduce existing stereotypes about criminals (Cavender and Bond-Maupin 1993:308).

An us-versus-them mentality pervades the storylines of crime dramas (Eschholz et al. 2004). Criminals are basically shown as evil and somehow less than human. Mental disturbance is another explanation for criminality offered by crime dramas. Gans-Boriskin and Wardle (2005) contended that violent depictions of mentally ill characters in Law $\mathcal{E}$ Order may suggest that crime is disproportionately committed by people with mental illnesses. However, the reaction of other characters to the offender's purported mental illness also suggests that such an explanation is not enough to counter the offender's culpability. In addition to mental disturbance, Fabianic (1997) noted that homicides in Law $\mathcal{E}$ Order were motivated by greed, vengeance, or an attempt to cover other crimes. Some people were simply killers. Detailed causative explanations were absent, reinforcing the notion that crime is caused by individual deficiencies rather than a reaction to structural or cultural forces. Television crime dramas reinforce the "fallacy of differences" by portraying homicide offenders as very different from everyone else, so that the cause of their behavior must by rooted in personal differences that existed prior to the crime (Fabianic 1997:202).

In their analysis of best-selling comics and trade paperbacks, Phillips and Strobl (2006) found that violent street crime was the theme most frequently present. Violent street crime, however, often served as a secondary theme or backdrop for other criminal activity. Organized crime was the most frequent primary theme, followed by government corruption and psychopathic criminality. If social problems were illustrated, they served as background or subplot. Based on their study of Superman and Batman comics, Vollum and Adkinson (2003) discerned that criminals tended to represent a threat to social order and were motivated by money, power, or revenge. Recurring antagonists were also interested in destruction and domination, an exaggerated version of the same 
motives. Nonetheless, Vollum and Adkinson (2003) concluded that the antagonists were portrayed as "rational criminals with rational goals" (p. 103). According to Stoddart (2006), comics, such as the Superman and Batman titles, locate the cause of crime in the debased individual who abuses and takes advantages of his/her rights with disregard for victims. Social forces, such as economic exploitation or inequality, are dismissed as irrelevant or remain unmentioned.

Surprisingly few studies have examined the motives for misdeeds and violence in children's programming. Klein and Shiffman (2008) examined the portrayal of assault in cartoons from the 1930s to the 1990s. Their count of implied motives for assault revealed that anger was the most common motive, followed by revenge, self-defense, and mean-spiritedness. Among the least frequent motives were protecting another character, jealousy, and greed. However, Klein and Shiffman's (2008) study did not disaggregate by genre or separate the actions of protagonists and antagonists. Wilson et al. (2002) studied how violence is portrayed in children's programs, disaggregating by genre but not by protagonists and antagonists. They found that the most common motives depicted across program types were personal gain, anger, and protection of life. In particular, superhero shows had the most violence deemed justified or morally correct and were most likely to feature violent acts undertaken for protection of life (presumably by protagonists), but least likely to show violence motivated solely by anger. Taken together, these two studies only share anger as a common motive, which may be an artifact of both failing to examine genres and failing to compare the motives of various characters within genres. In addition, neither study focused on the criminality of the characters or their actions.

\section{THE CURRENT STUDY}

In superhero comics, supervillains represent the antithesis of the moral order and mainstream values, and they have the ability to translate that antithetical stance into action (Coogan 2006). Their motives for illicit behavior focus around selfish antisocial pursuits, an attempt to gain wealth, power, and notoriety, or to otherwise work against legitimate society. They are personal motives that point to individual culpability. Although the superhero genre has a long-standing presence in children's television programming, little research has explored what messages about criminality are conveyed. Particularly for young viewers, few other sources of information about criminality are available. Thus, television media can play a key role in their early understanding about crime.

Following Adkinson (2008) and Phillips and Strobl (2006), who analyzed comic books through the lens of cultural criminology, the current study relies on insight from this perspective to explore how deviance and criminality are socially constructed within children's superhero cartoons. As articulated by Ferrell and Sanders (1995), cultural criminology draws on ideas from sociology, criminology, and cultural studies to explore and expose how cultural and criminal processes have converged in postmodern society. Cultural criminology implicates the media in producing (and reproducing) the intersection of crime and culture (Ferrell and Sanders 1995). Mediated images, meanings, and representations are central in defining criminality and social control (Ferrell 1999:396). Moreover, as they construct crime and control as social problems and political issues, the media also construct them as entertainment (Ferrell 1999:407). From this position, examining criminal images and representations is a means by which we can 
understand the "cultural raw material" that "interacts with and feeds into public attitudes and perspectives," fuels political rhetoric, and undergirds the dominant ideology of crime (Phillips and Strobl 2006:307).

\section{METHODS}

A content analysis was conducted to examine what messages about criminality and justice are incorporated into children's superhero shows. A purposive sample was drawn from three shows whose original airdates span 15 years, covering a high point in U.S. violent crime rates in the early 1990s, the subsequent decline during the later 1990s, and the post-9/11 period. The programs were: Batman: The Animated Series (1992-1995), Spider-Man: The Animated Series (1994-1998), and Justice League of America/Justice League Unlimited (2001-2006). The former two shows originally aired on Fox Kids Network, and the latter aired on Turner Broadcasting's Cartoon Network. Batman was a critically acclaimed series and generally regarded as a reinvention of the superhero cartoon genre (Misiroglu and Roach 2004). The artwork was more refined, the plots more elaborate, and the themes psychologically deeper than its predecessors. The shows that followed it, including Spider-Man and Justice League, also took this more sophisticated approach. (Justice League actually used some of the same production team and voice actors.) As of this writing, all three series continue to be aired on cable/satellite networks marketed to young viewers, including DisneyXD, The Hub, and Boomerang. In addition, all series are available on DVD and many episodes are viewable on the Internet.

Episode synopses were reviewed to eliminate episodes with non-human antagonists (i.e., aliens, paranormal entities). Then, episodes were selected so that there was representative coverage for all seasons of each show. If one part of a multi-part episode was selected, both parts were included in the sample. Fifteen to sixteen episodes of each show were selected, with a final sample size of 47 individual episodes viewed.

An open-ended coding rubric was utilized to guide viewing of two coders. Notes were compared for inter-rater reliability. Coding included observations of the main and supporting characters, their dialogue, and their actions. Observations were also made of the context of the characters' actions, such as the crime scene, antagonists' hideouts, and protagonists' headquarters. For the purposes of the current article, the focus was on verbal explanations for criminal behavior as well as non-verbal cues or explanations implied by the visual context or mood. More than one explanation could be used in an episode, and more than one explanation could be used per character.

\section{RESULTS}

\section{Explaining Criminal Behavior}

Figure 1 depicts the frequency with which various explanations of criminal behavior appeared, either verbally or non-verbally, across all three shows. The most common verbal explanations for behavior, usually offered by bystanders in the action or by the villains themselves, were "crazy," greed, and revenge. The non-verbal descriptions were either implied the characters' actions (e.g., money changing hands), reactions (e.g., expressions of outrage), or by the visual nature or mood of the crime scene. 


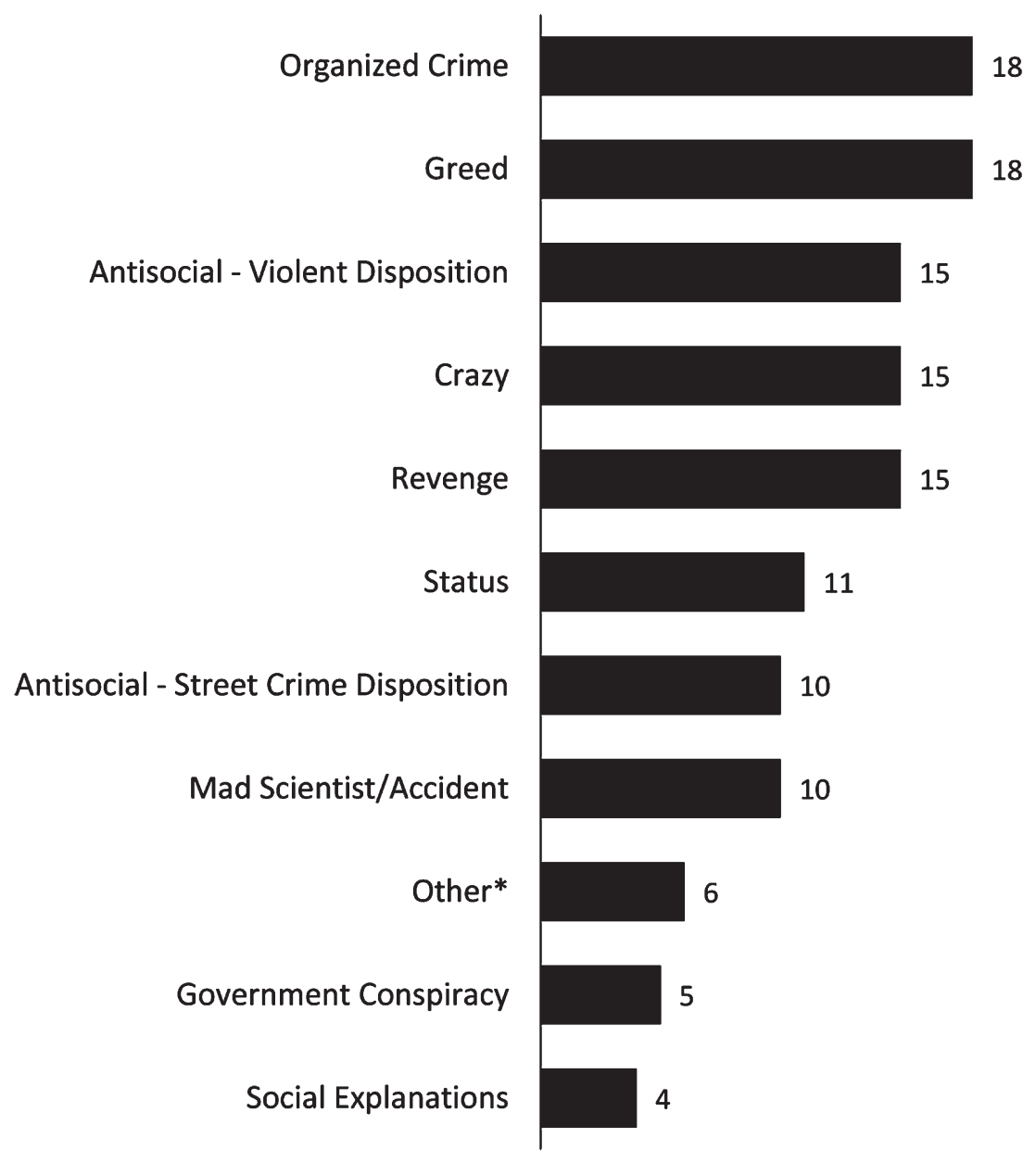

Figure 1. Frequency of explanations or motivations for criminal behavior.

* This category includes explanations that did not fit into other categories, such as "monster" (when characters were actually monstrous).

Organized crime and greed were the most frequent explanations for criminal behavior. Organized crime, generally depicted in the visual nature of the criminal activity, is discussed in greater detail below. Money was a recurrent topic among antagonists. In some cases, the initial act of larceny or robbery was to finance larger schemes. In other cases, accomplices had to be paid for their services. Yet other activities were undertaken for pure profit or to pay off debt. Greed was expressed both by dialogue and non-verbal cues. For example, in Justice League "The Cat and the Canary," Green Arrow and Black Canary attempt to gain information from a character that could best be described as a street hustler. During the encounter, Green Arrow entices the hustler with money. The hustler, at first annoyed, changes his attitude when he sees the cash: he rubs his hands together, snatches the money, counts it, then takes a cocky pose and demands more money in exchange for information. Throughout the three programs, the love of money was at the root of much evil. 
The antisocial-violent disposition, craziness, and revenge were the next most frequent explanations. The behavior of antisocial-violent characters, described verbally and nonverbally through the threat of violence or criminal action, is discussed below. Craziness was usually expressed by other characters. Bystanders would shout quips like, "You're crazy!" in response to villains' criminal or socially disruptive antics. In this context, the crazy label suggested that criminals have a different mentality than other people. In discussions about how to stop or capture a villain, law enforcement and heroes would refer to a villain's unbalanced nature. In this context, the crazy label implied that criminals are unpredictable and therefore dangerous.

In contrast to the application of the crazy label by others, revenge was expressed by the antagonists in the course of their scheming or in their interactions with other characters. An antagonist's desire for revenge could be directed at various targets. Heroes were common targets, as were criminal justice officials, both of whom were seen as responsible for thwarting antagonists in the past. In Batman "I Am the Night," the Jazz Man grumbles to another inmate that police Commissioner Gordon busted him: "[W]ould've been the best score of my life. I owe him big-time." Some antagonists directed their revenge at former peers for real or perceived slights. For example, in Spider-Man "The Ultimate Slayer" Alistair Smythe wants to enact a "terrible revenge" on Norman Osborn because he believes Osborn is responsible for his father's death.

Like revenge, a desire for status was expressed by the antagonists in the course of their plotting or interactions with others. As an explanation for criminal behavior, the desire for status can be divided into two categories. First, an antagonist could express a desire to achieve status among legitimate people. In Batman "Birds of a Feather," Penguin is released from prison and attempts to make in-roads with Gotham's upper crust. He is welcomed, but only as a form of entertainment and mockery, later leading him to kidnap a socialite when he discovers high society has made a fool of him. Second, an antagonist could express a desire to achieve status among other criminals. In Justice League "Only a Dream," John Dee, alias Dr. Destiny, fantasizes about destroying the League while all the supervillains cheer him, express their admiration, and tell him "You're one of us now."

Scientific experiments gone wrong also served as explanations for criminal or other antisocial activity, particularly in Spider-Man, with characters like Dr. Octopus, the Spider-Slayer, the Lizard, and the Scorpion. Dr. Octavius, Peter Parker's former teacher, becomes fused to the risky invention he insisted on testing and transforms into Dr. Octopus. He abducts the daughter of the family whose foundation denied his grant in "Armed and Dangerous." He destroys the lab and invention of a former colleague he accuses of stealing his ideas in "Make a Wish." In "Attack of the Octobot," he views himself as a "scientist devoted the betterment of all mankind," but feels his enemies keep him from the resources he needs. "Mad" scientists like Dr. Octopus engage in extreme forms of science that ultimately lead them to commit crime to further their scientific achievements. Scientific experiments also lead to accidents that fundamentally change, physically and mentally, an antagonist. As Coogan (2006) noted, in the comics, these characters already have some personal flaw, such as excessive ambition, but the transformation exaggerates the flaw while giving the character new powers to create harm and seek revenge or status.

In contrast, the antisocial-street criminal disposition, denoting the behavior of those characters engaged in solely in street crime, was not explained in detail. Their law-breaking behavior brought them into contact with heroes or law enforcement, either as a sub- 
plot or a plot device. Street criminals could also be in the employ of the main antagonists. Characters engaged in street crime were depicted or referred to as antisocial "thugs" or "scum." In other words, the behavior of common criminals seems to be in their natures; they are just bad guys (Coogan 2006).

Government conspiracy figured into an ongoing story arc in Justice League. A group of government officials views the League as a threat, primarily because these officials could not control the League for their own purposes. As a result, these officials, led by Amanda Waller, try various illicit means to destroy the League, including creating (literally) their own group of heroes who later went rogue, hiring a group of infamous assassins, and joining forces with Lex Luthor. Each conspiratorial plot is eventually uncovered by the League. ${ }^{1}$

Social explanations were the least frequent. A short story arc in Spider-Man included a subplot in which the son of Peter Parker's co-worker gets involved in a gang. The subplot featured Randy Robertson's declining relationship with his parents and his subsequent trip down the wrong path, marked by a deviant peer group, as well as Randy's doubt of Spider-Man's integrity. A two-part episode of Batman, "The Cat and the Claw," included a subplot in which Selina Kyle, also known as Catwoman, engages in various crimes to finance an animal preserve and to undermine a suspicious business venture on the property. Lastly, in Justice League "Hawk and Dove," social problems like poverty, prejudice, and inequality were explicitly offered as causes for violence and war crimes.

The following sections highlight prominent themes that emerged from the analysis. These were: the possibility of redemption and the power of stigma; the un-commonality of criminals; the prominence of organized crime; the unyielding antisocial-violent criminal; and the core causes of criminal behavior.

\section{Redemption and Stigma}

The possibilities for the redemption or rehabilitation of antagonists were limited. Redemption was only possible for worthy characters, who were showcased in forgiveness, reconciliation, or change-of-heart scenes. Worthiness was typically defined by the youth of a character. Young people who had somehow become entangled with crime were saved by the hero. For example, as mentioned earlier, Robbie Robertson's son Randy became entangled in a gang led by Tombstone (a childhood friend of Robbie's). In the end, Randy breaks free of the gang, accepts the consequences of his actions, and reconciles with his father. For the most part, main antagonists and supervillains were not worthy. Although Spider-Man regularly dealt with the moral fall of characters, these episodes did not deal with them after their capture. In Batman's Gotham, captured villains were sent to Arkham Asylum for the criminally insane, which was visually depicted as a dark prison rather than a hospital.

A few episodes portrayed the power of stigma on antagonists. As noted above, the Penguin's desire to fit into high society, despite presenting the appropriate aires, is foiled

1. To an adult viewer, the conspiracy story arc, in which secret government activity attempted to undermine the purer form of justice represented by the League, could be considered a critique of government activity post-9/11. In fact, an episode titled "Patriot Act" depicted a monstrous (literally) military official attempting to crush a group of heroes, including police, firefighters, and non-powered League members, being honored by a parade. The monster eventually turned his wrath on civilian bystanders, including children and an elderly woman. 
by the stigma he experienced, and he reverts to criminal behavior. The Riddler, in the ironically titled "Riddler's Reform," is well received by the business community after his release, appears to go straight, but Batman continually doubts his antagonist's ability to change. Batman is ultimately proved right when he uncovers the Riddler's devious plot. In both cases, the stigma experienced by characters prevented them from getting fair treatment by others in the community or a fair chance at change or reform. Inevitably, these characters would commit another crime, but rather than point to the power of labeling, the dialogue and storyline would fall back on the messages about criminality that were already established. Recidivism was viewed by others as revealing the offender's true nature-his or her inherent badness - a point of view the audience was encouraged to take.

\section{Criminals? Yes. But Common? Most Certainly Not $^{2}$}

The main antagonists were distinguished from the ordinary street criminals they sometimes employed as accomplices. First, as part of the cartoons' storytelling, the plots rapidly narrowed the focus to the interaction between the heroes and the major villains, relegating accomplices to the background. Second, the heroes, and to a lesser extent law enforcement, focused their efforts on the villains, quickly dispensing with any accomplices that might stand in the way. Third, as illustrated by Lex Luthor's quip (title to this section) to other supervillains he assembled to bring down the Justice League, the main villains viewed themselves as a class apart and above common street criminals. Consistent with their comic book origins, the stories revolved around supervillains or crime lords. Coogan (2006) noted that in comics, the disassociation with an ordinary identity exaggerates the villains' character flaws as well as their disconnect from legitimate society. Although these characters may not be common criminals, it was through these characters that the main messages about criminality were expressed.

\section{Organized Crime}

Organized crime was a recurrent theme in the three shows. In particular, Spider-Man confronted the aptly named Kingpin, and Batman contended with crime boss Rupert Thorne. Heroes in the Justice League also met organized crime figures like Steve Mandragora. Organized crime was depicted in the visual nature of the criminal activity. These characters and their accomplices or henchmen were often shown involved in vague criminal activities, such as meeting in darkened warehouses or transporting dubious looking boxes from place to place. During these vague activities, the characters verbally conspired against law enforcement or heroes in ways to avoid detection. In short, their actions were literally and figuratively shady.

Organized crime bosses were distinguished from the henchmen in their employ. Organized criminals had resources at their disposals that afforded them the ability to unfold master plans and fund the technologies and personnel needed to commit elaborate crimes. Henchmen, on the other hand, though sometimes clearly motivated by loyalty to the crime boss or by greed, were generally shown to be unintelligent, foolish, and expendable. It seemed that the crime bosses were rarely captured or punished, although their accomplices were. When it came to understanding the behavior of organized crime 
lords, Spider-Man's nemesis Green Goblin offered a concise explanation when chastising Kingpin: "Your sins are matched only by your size." 3 The massive physical size and opulent lifestyle of crime bosses like Kingpin and Thorne were symbolic of their motivations: power, gluttony, and greed.

\section{The Antisocial-Violent Criminal: Lex Luthor Versus the Joker}

The antisocial-violent disposition explanation was most frequently offered through the actions and expressions of the supervillains. These characters were defined as antisocial because they plotted against or resisted the heroes, with little to no concern for who might get hurt or other negative consequences to persons or property. At the same time, their scheming and plotting revealed that these characters were purposeful in their behavior. Unlike so-called crazy characters, such as Batman's former friend Two-Face, whose behavior was driven by an assumed mental disturbance, the antisocial-violent were in control of their mental facilities and exploited them. Unlike characters whose deviance was rooted in scientific experiments gone wrong, such as Spider-Man's nemesis Dr. Octopus, the antisocial-violent were evil at their cores.

Among the antisocial-violent, a dichotomy emerged, best represented by the Justice League's frequent foe Lex Luthor and Batman's recurring rival the Joker. Indeed, a twopart episode of Justice League, "Injustice for All," brought these two supervillains together with other villains loosely united to undo the League. In this and other episodes, both Lex and the Joker had plans for, at various points, destruction, domination, anarchy, revenge, and retaliation. On the one hand, Lex represents the lucid and diabolical criminal bent on destruction for personal gain and power. On the other hand, the Joker represents the unpredictable and maniacal criminal bent on chaos for personal pleasure. Regardless of the motivation $d u$ jour, these antisocial-violent antagonists were shown to be cold and calculating in their efforts to thwart the heroes and pursue self-interest.

\section{The Core Causes of Criminal Behavior}

Although multiple explanations were offered for criminality across the shows, two overarching messages emerged. First, true criminals are different from law-abiding people. Similar to Fabianic's (1997) analysis of homicide in Law \& Order, the depiction of criminality in the three cartoons supported the fallacy of differences. The message is that criminals are different than us and that it is something inherent about them that lead them to commit crime. Second, criminals, even if physically or mentally flawed, are rational and therefore culpable actors. Criminals are flagrantly willing to violate the law and the heroes in the furtherance of their own ambitions. The message is that criminals are evil-doers that purposely disrupt the social and moral order.

Both of these messages were clearly evident in "Trial," an episode of Batman in which the villains kidnap both Batman and Gotham's district attorney (who had previously expressed distaste with Batman's mode of justice). With the Joker serving as judge, the D.A. 
is forced to defend Batman against the accusations of Gotham's villains, who blame Batman for their criminal behavior. As the mock trial draws to a close, the D.A. makes her closing argument:

"Now I see that nearly every one of you would have wound up exactly the same, Batman or not. Oh, the gimmicks might be different, but you'd all be out there in some form or another bringing misery to Gotham. The truth is, you created him."

The jury, made up of a who's who of Gotham's villains, renders a not guilty verdict, absolving Batman. To this, the Joker responds: "We in fact messed up our own rotten lives, but we are so rotten, vile, and depraved, we're going to waste you anyway."

In short, criminals are individually responsible for their behavior. They are differentbad - at their cores, and purposefully engage in antisocial behavior.

\section{DISCUSSION}

The portrayal of crime and the stated or implied causes of crime on television are important because they produce and reproduce the prevailing ideology regarding crime (Fabianic 1997:196). That ideology rests on the image of the criminal as a rational yet evil person who freely chooses antisocial behavior (Kappeler and Potter 2005; Melossi 2000). Scholarly interest in the mediated construction of crime has commonly focused on media forms targeted to adult audiences. Programming targeted to children has received less attention in this regard, even while the debate about the level of violence present in children's media continues. Superhero cartoons, because they have roots in an established genre and regularly deal with crime issues, are an ideal location for analyzing what mediated messages about criminality children may be receiving.

Through the lens of cultural criminology, a content analysis of three superhero cartoons covering a 15-year span-Batman: The Animated Series (1992-1995), Spider-Man: The Animated Series (1994-1998), and Justice League of America/Justice League Unlimited (20012006) - was undertaken. Cultural criminology focuses on the intersection of crime and culture and how the processes of social construction occur in a media-saturated environment (Ferrell and Sanders 1995). Superhero cartoons, although clearly constructing crime as entertainment, are also a potential source of information for a young person who may have limited exposure to other sources of crime-related information. Like other media, images and meanings about crime are packaged, formatted, and sold as information about the world (Surette 2003). As such, crime in these programs is a commodity that communicates a particular ideological content (Dotter 2002).

As Surette (2003) argues, in this commoditized form, descriptions of crime are common, but explanations of criminality are rare or simplistic. In keeping with this assessment, the current analysis revealed that in-depth explanations for criminality were absent from these shows. Instead, clues to understanding or explaining antisocial behaviors were given by the antagonists themselves, the heroes, or other characters. Non-verbal clues were also apparent, in which explanations were implied by the actions of characters or the setting itself. Organized crime and greed topped the list for most frequent explanations, followed by an antisocial-violent disposition, craziness, and revenge. Social factors, such as poor parental relationships, deviant peers, or poverty, were least frequent. These themes reflect those present in the comics on which the shows were based (e.g., Vollum and Adkinson 2003). 
In-depth explanations were only provided for the few criminals who were portrayed as redeemable, similar to Maruna's (2001) assertion that society requires a "sad tale" to make deviants forgivable (p. 145). For the rest of the antagonists, storylines reinforced the dominant ideology of crime by emphasizing individual-level faults. The specific explanations for their behaviors were in many ways secondary to the juxtaposition of the antagonists against the protagonists. Newman (1993) argued that in comics "evil is good perverted" (p. 309). In the cartoons analyzed, if someone resisted or violated the social order, as represented by the heroes, then that character was unquestionably in the wrong. In other words, viewers know the villains are different and bad because they oppose the hero, the police, and the social and moral order. The narrative about crime is thus shortened and situated in the ideology of choice and control (Dotter 2002).

The major villains in the three cartoons were set apart from the common criminals, but it was the depiction of the supervillains' behaviors that provided the strongest messages about criminality. Consistent with analyses of news reporting (Barlow et al. 1995; Welsh et al. 1998), these messages included themes of utilitarianism and personal pathology. However, as Gans-Boriskin and Wardle (2005) found in adult crime dramas, evidence of pathology did not remove culpability. First, criminal activity, exemplified by organized crime, centers on greed: greed for wealth, for power, for self-aggrandizement. Second, criminals, exemplified by Lex Luthor and the Joker, are aware of right and wrong; yet, they flaunt the moral order in calculated ways so that they may seek their own self-interests. Third, criminals are intrinsically different from $u s$, but because their evil remains rational, they remain completely culpable for their actions.

Overall, the analysis suggests that children's superhero cartoons provide children introductory lessons about criminality that are consistent with dominant ideology in the United States. Like representations across entertainment media, criminals in superhero cartoons are predatory people whose behavior is rooted in personal faults, who freely choose their behavior, who are not constrained by normal rules and values, and who are different from us (Surette 1994). In short, criminals are bad seeds (Sanders and Lyon 1995). Furthermore, the constructions of criminality in superhero cartoons are consistent with the formulation of criminality present in other forms of mainstream media marketed to adults (Cavender 1998; Eschholz et al. 2004). Early messages are thus reinforced by later messages about who does crime and why they do it.

Certainly, storytelling about crime, in which a predatory or evil criminal is pursued by the forces of good, has extensive historical roots (Kooistra and Mahoney 1999; Surette 1994). Superheroes, first in comics and then in audio-visual media, have decades-long histories and storylines that draw on traditional themes (Coogan 2006; Fingeroth 2004). Meyer and Bogdan (1999) contend that one cultural practice through which children learn cultural messages is the telling of traditional stories. Traditional tales, and their implicit messages about deviance, are important elements in childhood socialization and the internalization of cultural beliefs. Yet, the processes of constructing and reconstructing the criminal image and its meaning over time, particularly in an increasingly media-saturated culture, has contributed to an image of crime, as portrayed to children and adults, that is iconic and ideologically powerful (Surette 1994).

As with any content analysis, we are unsure as to how an actual viewer may process the images and messages they receive. In other words, the current study cannot determine how the audience consumes, processes, and reproduces the images and their meanings (Websdale and Ferrell 1998). Future research should consider how children interpret the images and messages in superhero programs to determine if they are receiving the 
same messages about criminality detected by adult analysts (see Tobin 2000). Audiences should also not be viewed as passive receptacles, especially as they cognitively and emotional mature; rather, audiences should be viewed as negotiating or even resisting and reconstructing images and meanings (Kappeler and Potter 2005). Future research should also consider how audience interpretations develop with age to understand if and how early messages are reinforced by later messages.

In conclusion, the superhero cartoons analyzed here reinforce the dominant ideology of crime centered on individual responsibility, rational choice, and the evil "other." In doing so, they support the concomitant ideologies of social control. Consistent with Sacco's (1995) assessment of other media, the crime problem in superhero cartoons is framed so that the primary responsibility of providing a solution is placed on the heroes (as representative of the justice system), rather than on the social conditions or power relationships that are the root causes of crime.

\section{REFERENCES}

Adkinson, Cary D. 2008. “The Amazing Spider-Man and the Evolution of the Comics Code: A Case Study in Cultural Criminology." Journal of Criminal Justice and Popular Culture 15:241-261.

Barak, Gregg. 1994. "Media, Society, and Criminology." Pp. 3-48 in Media, Process, and the Social Construction of Crime: Studies in Newsmaking Criminology, edited by G. Barak. New York: Garland Publishing Inc.

Barlow, Melissa Hickman, David E. Barlow, and Theodore G. Chiricos. 1995. "Mobilizing Support for Social Control in a Declining Economy: Exploring Ideologies of Crime within Crime News." Crime and Delinquency 41:191-204.

Blumberg, Fran C., Kristen P. Bierwirth, and Allison J. Schwartz. 2008. “Does Cartoon Violence Beget Aggressive Behavior in Real Life? An Opposing View." Early Childhood Education Journal 36:101-104.

Cavender, Gray. 1998. "In 'The Shadow of Shadows': Television Reality Crime Programming." Pp. 79-94 in Entertaining Crime, edited by M. Fishman and G. Cavender. New York: Aldine de Gruyter.

. 2004. "Media and Crime Policy: A Reconsideration of David Garland's The Culture of Control." Punishment and Society 6:335-348.

Cavender, Gray and Lisa Bond-Maupin. 1993. "Fear and Loathing on Reality Television: An Analysis of 'America's Most Wanted' and 'Unsolved Mysteries."' Sociological Inquiry 63:305-317.

Coogan, Peter. 2006. Superhero: Secret Origin of a Genre. Austin, TX: MonkeyBrain Books.

Donovan, Pamela. 1998. "Armed with the Power of Television: Reality Crime Programming and the Reconstruction of Law and Order in the United States." Pp. 117-137 in Entertaining Crime, edited by M. Fishman and G. Cavender. New York: Aldine de Gruyter.

Dotter, Daniel. 2002. "Creating Deviance: Scenarios of Stigmatization in Postmodern Media Culture." Deviant Behavior 23:419-448.

Eschholz, Sarah, Matthew Mallard, and Stacey Flynn. 2004. “Images of Prime Time Justice: A Content Analysis of 'NYPD Blue' and 'Law and Order.'" Journal of Criminal Justice and Popular Culture 10:161-180.

Fabianic, David. 1997. "Television Dramas and Homicide Causation." Journal of Criminal Justice 25:195-203.

Ferrell, Jeff. 1999. “Cultural Criminology.” Annual Review of Sociology 25:395-418.

Ferrell, Jeff and Clinton R. Sanders. 1995. Cultural Criminology. Boston: Northeastern University 
Press.

Fingeroth, Danny. 2004. Superman on the Couch: What Superheroes Really Tell Us about Ourselves and Our Society. New York: Continuum.

Frost, Natalie. 2010. “Beyond Public Opinion Polls: Punitive Public Sentiment and Criminal Justice Policy." Sociology Compass 4:156-168.

Gans-Boriskin, Rachel and Clair Wardle. 2005. "Mad or Bad? Negotiating the Boundaries of Mental Illness on 'Law and Order."' Journal of Criminal Justice and Popular Culture 12:26-46.

Garland, David. 2001. The Cultural of Control: Crime and Social Order in Contemporary Society. Chicago: University of Chicago Press.

Hagan, John. 2010. Who Are the Criminals? The Politics of Crime Policy from the Age of Roosevelt to the Age of Reagan. Princeton, NJ: Princeton University Press.

Ismaili, Karim. 2003. "Explaining the Cultural and Symbolic Resonance of Zero Tolerance in Contemporary Criminal Justice." Contemporary Justice Review 6:255-264.

Kappeler, Victor E. and Gary W. Potter. 2005. The Mythology of Crime and Criminal Justice, 4th ed. Long Grove, IL: Waveland Press.

Klein, Hugh and Kenneth S. Shiffman. 2008. "What Animated Cartoons Tell Viewers about Assault." Journal of Aggression, Maltreatment, and Trauma 16:181-201.

Kooistra, Paul G. and John S. Mahoney, Jr. 1999. “The Historical Roots of Tabloid TV Crime." Pp. 47-71 in Making Trouble: Cultural Constructions of Crime, Deviance, and Control, edited by J. Ferrell and N. Websdale. New York: Aldine de Gruyter.

Kooistra, Paul G., John S. Mahoney Jr., and Saundra D. Westervelt. 1998. "The World of Crime According to 'Cops."' Pp. 141-158 in Entertaining Crime, edited by M. Fishman and G. Cavender. New York: Aldine de Gruyter.

Lofquist, William S. 1997. “Constructing 'Crime': Media Coverage of Individual and Organizational Wrongdoing." Justice Quarterly 14:243-263.

Lynch, Michael J. and Lenny A. Krzycki. 1998. "Popular Culture as an Ideological Mask: Mass-Produced Popular Culture and the Remaking of Criminal Justice-Related Imagery." Journal of Criminal Justice 26:321-336.

Maruna, Shadd. 2001. Making Good: How Ex-Convicts Reform and Rebuild Their Lives. Washington, DC: American Psychological Association.

Melossi, Dario. 2000. "Changing Representations of the Criminal." British Journal of Criminology 40:296-320.

Meyer, Jon; 'a F. with Gloria Bogdan. 1999. “The Elders Were Our Textbooks: The Importance of Traditional Stories in Social Control." Pp. 25-46 in Making Trouble: Cultural Constructions of Crime, Deviance, and Control, edited by J. Ferrell and N. Websdale. New York: Aldine de Gruyter.

Misiroglu, Gina and David A. Roach. 2004. The Superhero Book: The Ultimate Encyclopedia of Comic Book Icons and Hollywood Icons. Detroit: Visible Ink Press.

Morris, Norval. 1997. "Crime, the Media, and our Public Discourse." Pp. 99-121 in Perspectives on Crime and Justice: 1996-1997 Lecture Series. Washington, DC: U.S. Department of Justice; accessed August 25, 2009 at http://www.ncjrs.gov/pdffiles/166609.pdf

Newman, Graeme. 1993. “Batman and Justice: The True Story." Humanity and Society 17:297-320.

Phillips, Nickie D. and Staci Strobl. 2006. "Cultural Criminology and Kryptonite: Apocalyptic and Retributive Constructions of Crime and Justice in Comic Books." Crime, Media, Culture 2:304-331.

Presdee, Mike. 2000. Cultural Criminology and the Carnival of Crime. London: Routledge.

Sacco, Vincent. 1995. "Media Constructions of Crime." Annals of the American Academy of Political and Social Sciences 539:141-154.

Sanders, Clinton R. and Eleanor Lyon. 1995. "Repetitive Retribution: Media Images and the Cultural Construction of Criminal Justice." Pp. 25-44 in Cultural Criminology, edited by J. Ferrell and 
C. R. Sanders. Boston: Northeastern University Press.

Shanahan, James. 2004. "A Return to Cultural Indicators." Communications 29:277-294.

Simon, Jonathan. 2007. Governing Through Crime: How the War on Crime Transformed American Democracy and Created a Culture of Fear. Oxford: Oxford University Press.

Stoddart, Mark C. J. 2006. “They Say It'll Kill Me ... But They Won't Say When! Drug Narratives in Comic Books." Journal of Criminal Justice and Popular Culture 13:66-95.

Surette, Ray. 1994. "Predator Criminals as Media Icons." Pp. 131-158 in Media, Process, and the Social Contruction of Crime: Studies in Newsmaking Criminology, edited by G. Barak. New York: Garland Publishing Inc.

. 1998. Media, Crime, and Criminal Justice: Images and Realities, 2nd ed. Belmont, CA: West/ Wadsworth.

. 2003. "The Media, the Public, and Criminal Justice Policy." Journal of the Institute of Justice and International Studies 2:39-52.

Tobin, Joseph. 2000. "Good Guys Don't Wear Hats." Children's Talk about the Media. New York: Teachers College Press.

Tonry, Michael. 2004. Thinking About Crime: Sense and Sensibility in American Penal Culture. Oxford: Oxford University Press.

Unnever, James D. and Francis T. Cullen. 2010. “The Social Sources of Americans' Punitiveness: A Test of Three Competing Models." Criminology 48:99-129.

Vollum, Scott and Cary. D. Adkinson. 2003. "The Portrayal of Crime and Justice in the Comic Book Superhero Mythos." Journal of Criminal Justice and Popular Culture 10:96-108.

Websdale, Neil and Jeff Ferrell. 1999. "Taking the Trouble: Concluding Remarks and Future Directions." Pp. 349-364 in Making Trouble: Cultural Constructions of Crime, Deviance, and Control, edited by J. Ferrell and N. Websdale. New York: Aldine de Gruyter.

Welsh, Michael, Melissa Fenwick, and Meredith Roberts. 1997. "Primary Definitions of Crime and Moral Panic: A Content Analysis of Experts' Quotes in Feature Newspaper Articles on Crime." Journal of Research in Crime and Delinquency 34:474-494.

Welsh, Michael, Melissa Fenwick, and Meredith Roberts. 1998. “State Managers, Intellectuals, and the Media: A Content Analysis of Ideology in Experts' Quotes in Feature Newspaper Articles on Crime." Justice Quarterly 15:219-241.

Wilson, Barbara J., Stacy L. Smith, W. James Potter, Dale Kunkel, Daniel Linz, Carolyn M. Colvin, and Edward Donnerstein. 2002. "Violence in Children's Television Programming: Assessing the Risks." Journal of Communication 52:5-35.

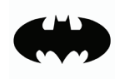

Lisa A. Kort-Butler is an Assistant Professor in the Department of Sociology at the University of Nebraska-Lincoln. Her research interests include the criminal behavior and well-being of adolescents and young adults, and media representations of criminal behavior, crime events, and the justice system. 